\title{
Espacios de poder en La Huerta, quebrada de Humahuaca
}

IVÁN LEIBOWICZ ${ }^{1}$

\section{RESUMEN}

La construcción y resignificación de espacios fue una estrategia del Imperio Inca en la conquista de todo su territorio. Aquí se aborda esta problemática en el sitio La Huerta en la quebrada de Humahuaca (Jujuy, Argentina), para entender cómo el poder imperial impuso una nueva espacialidad sobre las poblaciones conquistadas, reestructurando y resignificando el paisaje socialmente construido, y cómo la imposición de esta espacialidad ideológicamente constituida produjo y reprodujo las relaciones de dominación y poder promovidas por el Imperio. Para ello, humanizaremos este paisaje pensándolo con gente dentro de él, analizando el modo en que los sujetos se conducían en ese espacio tridimensional, lo experimentaban y percibían.

Palabras claves: dominación inca-espacialidad-paisaje social-poder.

\section{ABSTRACT}

The building and resignification of space was a conquest strategy of the Inca Empire deployed throughout its territory. This paper aims to examine the problem by considering the archaeological site of La Huerta (quebrada of Humahuaca, Jujuy, Argentina) We seek to understand how imperial power imposed its spatiality on conquered population, by re-building and re-signifying the socially-built landscape, and how the ideological representation of this spatiality, both produced and reproduced the empire's power relationships of domination. For this purpose, we humanize the landscape by thinking about it with people, analyzing how its inhabitants would have behaved in that tridimensional space, experiencing and perceiveing it.

Key words: Inka Rule - spatiality - social landscape - power.

Recibido: diciembre 2006. Aceptado: junio 2007.

\section{Introducción}

La producción y reestructuración del espacio socialmente construido fue uno de los medios que adoptó

1 Instituto de Arqueología, Facultad de Filosofía y Letras, Universidad de Buenos Aires. 25 de Mayo 217, $3^{\circ}$ piso, Buenos Aires, ARGENTINA. Email: pinocarriaga@ hotmail. com el Imperio Inca para crear, legitimar y testimoniar su poder. En este trabajo analizamos esta problemática en el sitio La Huerta (quebrada de Humahuaca), donde al momento de la conquista ( $c a .1410$ DC) el Imperio reconstruyó y resignificó el paisaje como una forma de articular el proceso de dominación.

Por ello, creemos que la inclusión del análisis del espacio es necesaria a la hora de interpretar y explicar los diversos procesos sociales que atraviesan una sociedad. En cualquier investigación sobre una sociedad, esté esta situada en cualquier tiempo o lugar, deben considerarse siempre sus características históricas particulares, y la relación dialéctica entre espacialidad y relaciones sociales no puede ser pasada por alto.

Consideramos entonces que la comprensión del arreglo espacial del sitio La Huerta durante el Período Tardío (900-1410 DC) es fundamental para comprender la forma que adoptó el proceso de dominación incaico, el cual culmina en 1536 DC, en cuanto a la construcción del paisaje social, y cómo la manipulación ideológica de la cultura material funcionó como estrategia de legitimación del control ejercido por el Imperio sobre las sociedades conquistadas.

Estableceremos, tomando en cuenta el análisis de las propiedades visuales de las estructuras y su distribución espacial, el modo en que la construcción de un nuevo paisaje social articuló el proceso de dominación y control inca en el sitio La Huerta. A su vez, trataremos de comprender cómo y en qué magnitud esta nueva espacialidad impactó en las percepciones que tenían sobre ésta las poblaciones conquistadas, es decir, intentaremos entender la forma en que el Imperio introdujo una nueva forma de vivir y experimentar el paisaje.

\section{La espacialidad en arqueología}

Es fundamental comprender que el espacio no es solo un contenedor de las acciones humanas, el telón de fondo o la escenografía de la vida social. Los lugares, los paisajes donde se llevan a cabo 
determinadas prácticas sociales o donde se plasman ciertas relaciones sociales son parte constitutiva de las mismas. De esta manera la espacialidad y las acciones y relaciones sociales se constituyen en una relación dialéctica. Estas últimas moldean paisajes al tiempo que la espacialidad produce y reproduce relaciones sociales, prácticas e identidades (Soja 1989). Vemos así como la vida social se encuentra estructurada espacio-temporalmente y como la espacialidad da forma a las prácticas recursivas de la vida cotidiana (Soja 1985).

Es entonces necesario destacar que este espacio se encuentra ideológicamente construido para afectar la percepción que se tiene sobre el mismo (Acuto 1999a), siendo la construcción de estructuras un acto político e ideológico (Miller y Tilley 1983). De esta forma las contradicciones y tensiones sociopolíticas particulares de cualquier sociedad en la historia se manifiestan espacialmente (Lefebvre 1985 cit. en Hayden 1997). Las luchas por el poder, por imponer discursos, percepciones, modos de entender el mundo, tienen su correlato espacial. Se trata de generar espacialidades que produzcan y reproduzcan relaciones de control y dominación. De esta manera el espacio da forma a la reproducción social, la espacialidad reproduce a la sociedad, siendo una manifestación real de las relaciones sociales.

Así, entendemos al espacio como un producto material de la acción humana que no puede ser experimentado de una forma neutral o inocente (Thomas 1993). Es un producto social, una consecuencia de la transformación colectiva humana de la naturaleza (Cosgrove 1984). Lejos de conductas pasivas y meramente adaptativas, la gente se comporta de manera activa en el espacio, ordena, transforma, se identifica y memoriza paisajes (Ashmore y Knapp 1999). Como señala Palma (2000), los asentamientos humanos configuran un paisaje socialmente construido que testimonia y legitima el ejercicio del poder en dicho espacio.

Por otra parte, entendemos que en los paisajes, los edificios tienen la capacidad de producir y difundir significados, que están cargados de sentidos a la vez que representan un pensamiento, una ideología particular. Podemos entenderlos, entonces, como un sistema de significación a través del cual la sociedad se reproduce y transforma (Tilley 1994), donde el significado se produce a través del funcionamiento dinámico de las relaciones entre personas, cosas y lugares (Thomas 2001: 180). Así, vemos como los sujetos se constituyen tanto espacial como materialmente y el espacio se convierte en un lugar para la producción y consolidación de significados (Thomas 1996). El espacio es fundamental en cualquier forma de vida en sociedad, en todo ejercicio de poder, de manera que la repetida concurrencia a lugares, a espacios creados a través de la arquitectura, genera rutinas y colabora en la reproducción social (Thomas 1993).

El espacio del paisaje es cultural y natural al mismo tiempo; conecta valores, modos de percepción y representación, experiencias, artefactos, historias, sueños, identidades, narraciones y recuerdos (Shanks 2000). El ambiente construido se vuelve entonces una expresión de procesos y estructuras mentales culturalmente compartidas (Lawrence y Low 1990: 468).

De este modo, vemos claramente cómo el tránsito cotidiano, así como el de tipo ocasional o estacional de los seres humanos por un determinado espacio delineado socialmente, genera y reproduce relaciones sociales que incluyen formas particulares de comprender, observar y sentir el mundo que los rodea; cómo determinadas espacialidades atravesadas por conceptos ideológicos producen y guían determinadas formas de experimentar el espacio material. Así, la relación entre ideología y espacialidad se torna fundamental en nuestro análisis. Más aún teniendo en cuenta que a través de la construcción de estructuras y de la reestructuración y resignificación del espacio, es su ideología lo que el Imperio Inca intenta imponer.

Considerando la constitución ideológica del espacio, podemos observar que la ideología como concepción del mundo se introduce en la vida práctica de las personas a la vez que construye y alienta su práctica social. La ideología y el poder no pueden pensarse sin una vinculación a prácticas sociales, y como componentes de la praxis humana tienen su correlato material (Miller y Tilley 1983). La ideología se manifiesta en actos insertos en prácticas, y éstas están reguladas por rituales que se inscriben en el seno de la existencia material de un aparato ideológico (Althusser 1988). Es decir, observamos la existencia material de la ideología plasmada en prácticas ideológicas, rituales e instituciones. Los elementos materiales son una manifestación de una determinada forma social a la vez que le dan forma a la misma (Dant 1999). 
Así, podemos ver cómo la ideología utiliza medios materiales para comunicarse, cómo existe una necesidad de comunicar materialmente (Nielsen 1995b), y cómo la arquitectura es uno de estos medios. Es más, podría considerarse uno de los indicadores más poderosos de la dominación, ya que las prácticas ideológicas involucran objetos, estructuras, monumentos y personas, y no sólo ideas (Nielsen y Walker 1999). La arquitectura se convierte de este modo en un medio de control social, siendo modelada por la ideología dominante al tiempo que es un instrumento clave en la producción social de significado (Moore 1996).

A su vez, la cultura material es un elemento activo en las relaciones sociales y puede tanto reflejarlas como disfrazarlas. Puede entonces ser utilizada por las élites para legitimar su autoridad.

En el caso incaico, la arquitectura representa el poder y la autoridad del Imperio, jugando un rol central en su expansión (De Marrais et al. 1992), y se vuelve la mejor expresión simbólica de dominación a través de actos de fundación y refundación; más aún si se tiene en cuenta que para los incas dominar era sinónimo de edificar (Gallardo et al. 1995).

Cabe aclarar que no pretendemos observar la espacialidad o las construcciones arquitectónicas como si solo representasen la materialización de una ideología o determinadas relaciones sociales, ya que de esta manera estaríamos otorgándole a la cultura material un estatus pasivo, como si fuera tan solo un mero reflejo de éstas, sino que a lo largo de estas líneas se la considera un componente activo en la constitución de sujetos sociales, dando forma a la experiencia, produciendo y reproduciendo relaciones sociales.

\section{La expansión imperial y la construcción del paisaje}

Al momento de la conquista española el Tawantinsuyu contaba con una extensión de $1.700 .000 \mathrm{~km}^{2}$. Ocupaba parte de los territorios de los actuales Colombia, Ecuador, Perú, Bolivia, Chile y Argentina, fundamentalmente la región andina y la costa del Océano Pacífico. El territorio de este inmenso Imperio se encontraba dividido en cuatro partes o suyus: Chinchaysuyu, Antisuyu, Cuntisuyu у Collasuyu. Este último se extendía desde Cusco hacia el sur, abarcando el lago Titicaca y los territorios pertenecientes hoy a Bolivia, Chile y Argentina y era el más extenso de los cuatro con una superficie de $800.000 \mathrm{~km}^{2}$.

González (1980) al analizar el patrón de asentamiento estatal postula que la gran mayoría de los asentamientos incaicos en el Noroeste Argentino fueron emplazados en o sobre sitios tardíos, adaptándose a las características locales. Se ha considerado entonces que los incas aprovechaban la centralización preexistente y montaban sus centros sobre los anteriores focos de autoridad nativa, siendo indispensable la imposición de ciertos elementos mínimos de urbanismo para el crecimiento y sostenimiento de la sociedad estatal imperial (Morris 1973).

Veremos entonces cómo el Estado manipula y construye el paisaje articulando los procesos de dominación política y social. Esta es una característica en las conquistas del Imperio Inca a lo largo de su territorio, donde se observa que existe un concepto central en el trazado y planificación de los asentamientos, en los que la arquitectura transfiere un concepto, una ideología imperial (Hyslop 1990). La cognición incaica del paisaje fue embebida en una práctica controlada estatalmente, donde los urbanistas y artesanos eran conscientes de hacer en los sitios representaciones de la ideología estatal (Van de Gutche 1999). Entonces, a través del diseño de los sitios estatales se comunicaban preceptos políticos, religiosos y económicos generados en Cusco (Hyslop 1990).

Además, la apropiación por parte del Imperio Inca de lugares de significativa importancia para las poblaciones locales, fue una de las estrategias de dominación tanto en las áreas centrales como en las más periféricas de su territorio (p.e., Niles 1992; Rostworowski 1992; Meyers y Ulbert 1997; Cornejo 1999; Bauer y Stanish 2001; Eeckhout 2004).

Los incas modificaron el espacio socialmente construido de las innumerables y diversas poblaciones que incorporaron al Imperio de diferentes maneras. Este cambio afectó a los pueblos sometidos tanto a nivel material como simbólico, al tiempo que los incas ajustaban sus procesos de dominación, adecuándose a cada situación en particular (Hyslop 1990). De este modo, el Tawantinsuyu buscó reestructurar la experiencia espacial de las poblaciones locales como una forma de control y dominación, intentando imponer su cosmología e ideología (Acuto 1999a y b). Sin embargo, en pocos casos se conocen las formas en que la dominación incaica afectó y 
modificó la organización social y la vida cotidiana de las comunidades (Acuto et al. 2004).

\section{La Huerta de Huacalera}

La quebrada de Humahuaca (Figuras 1 y 2 ) fue anexada al Tawantinsuyu a comienzos del siglo XV. Mientras los relatos de los cronistas españoles sitúan el comienzo de esta conquista bajo el reinado del décimo soberano cusqueño, Topa Inka Yupanqui, alrededor del año 1480 DC, los fechados radiocarbónicos de los primeros niveles de ocupación incaica en La Huerta indican para ésta una fecha calibrada de 1412 DC (Palma 1998).

Con la llegada de los incas comienzan a aparecer en la región signos inequívocos de la acción imperial tales como el qhapaqñan o Camino Inca, los tambos, fortalezas, santuarios de altura y otros, aspectos propios de su cultura material. Durante esta etapa algunos sitios son abandonados casi por completo (p.e., Los Amarillos, Hornillos y Huella; Nielsen y Walker 1999: 166). En cambio en otros, como La Huerta, ocurre un gran crecimiento (Palma 1998, 2000). Aumentan también en esta época los campos de cultivo de Coctaca y Rodero, a la vez que nuevos sitios como Putuquito y Juire son creados para iguales fines (Nielsen 1995a).
La Huerta se encuentra a $3 \mathrm{~km}$ al este de la confluencia de las quebradas de Humahuaca y La Huerta, a $23^{\circ}$ $28^{\prime}$ Lat. Sur y $65^{\circ} 17^{\prime}$ Long. Oeste. Se emplaza en un espolón que baja del cerro Sisilera, a 2700 m.snm y a 10 y $50 \mathrm{~m}$ sobre los ríos La Huerta y Sisilera (Raffino y Alvis 1993; Palma 1998). Se trata de un gran conjunto semiurbano, de gran complejidad estructural interna que cuenta con 614 estructuras en superficie y 69 subterráneas, ocupando una superficie de 8.12 ha (Raffino 1988; Raffino y Alvis 1993; Palma 1998).

El sitio La Huerta es considerado una "protociudad" (Raffino 1988) en tiempos preincaicos, el cual sufrió profundas transformaciones durante la dominación incaica. Por un lado, una remodelación arquitectónica lo habría convertido en una cabecera administrativa (Raffino y Alvis 1993), y por otro, se habría transformado en un centro productor de textiles (Raffino y Palma 1993).

La remodelación de La Huerta, según las investigaciones que nos precedieron, parece haber quedado inconclusa (Raffino y Alvis 1993: 56). Esta situación se debe a la ausencia de una clásica cancha inca con recintos perimetrales compuestos (RPC), y a que carece de otras construcciones estatales como el ushnu o la aukaipata o plaza (Raffino 1988; Raffino y Alvis 1993; Palma 1998). No obstante, en el centro

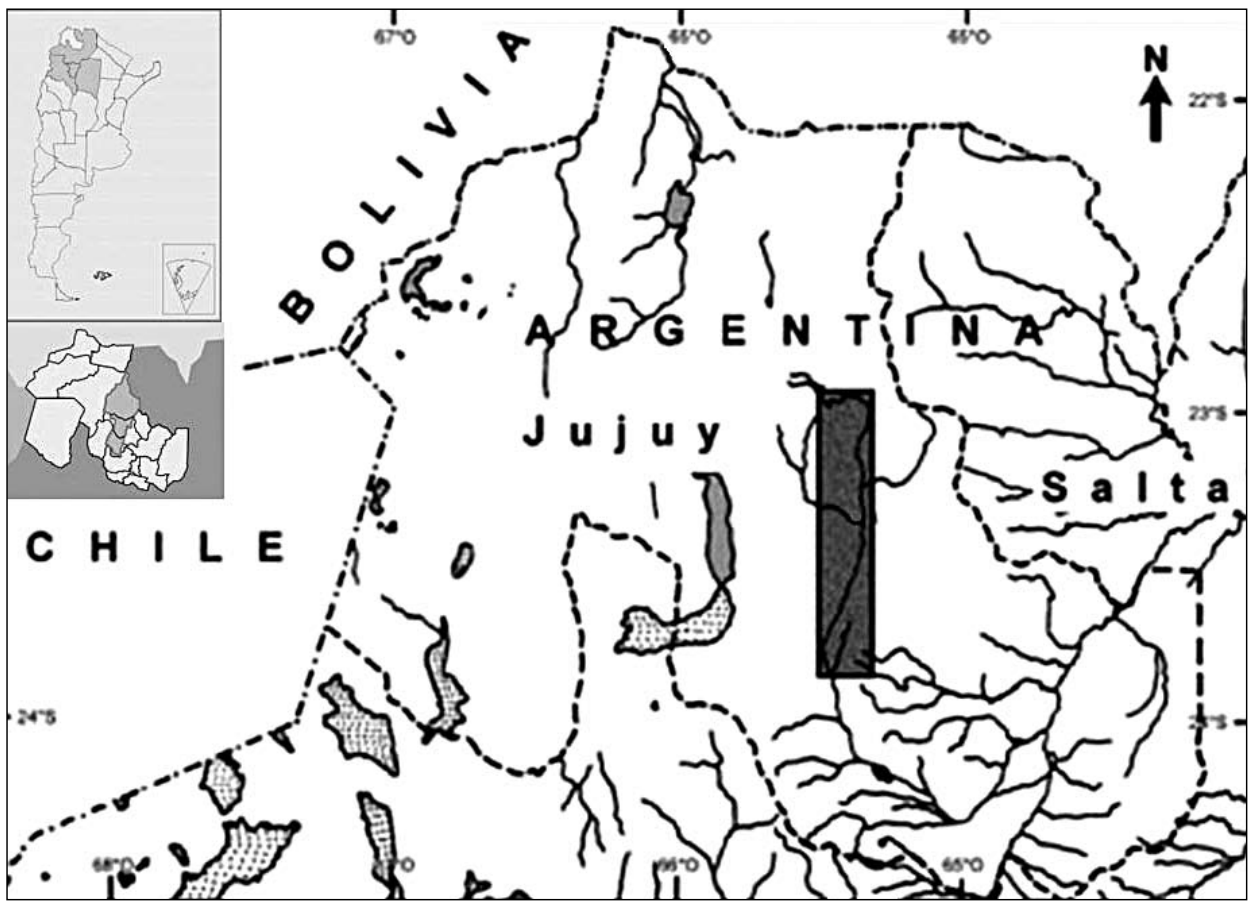

Figura 1. Ubicación de la quebrada de Humahuaca en Argentina. 


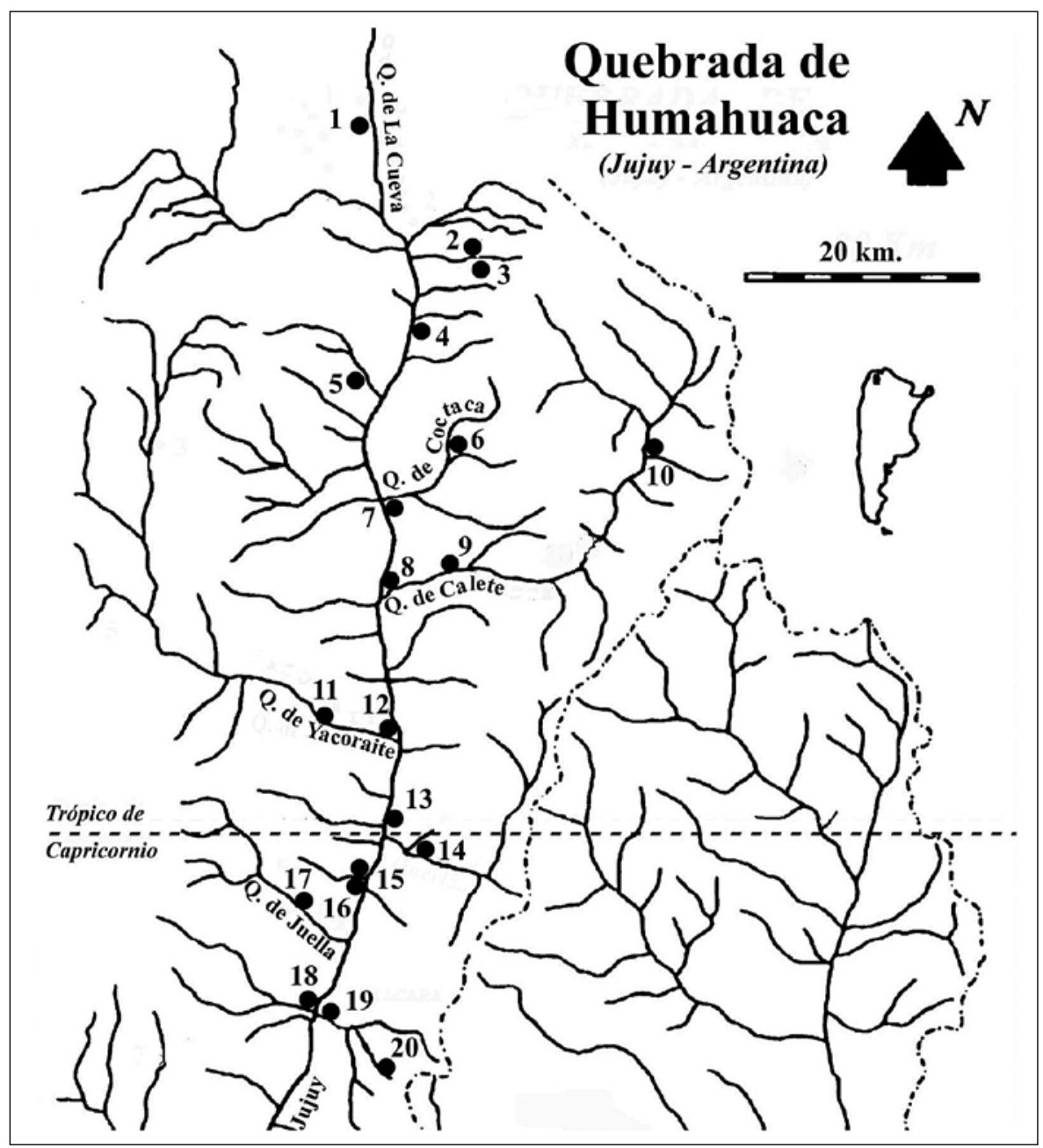

Figura 2. La quebrada de Humahuaca durante el Período Inca. Sitios: 1) P. Morado; 2) Putuquito; 3) Juire; 4) P. Rodero; 5) P. Hornadita; 6) Coctaca; 7) Peñas Blancas; 8) P. Calete; 9) P. Ucumazo; 10) Pta. de Zenta; 11) Los Amarillos; 12) Yacoraite; 13) Campo Morado; 14) La Huerta; 15) Perchel; 16) Angosto Chico; 17) Juella; 18) Huichairas; 19) Pucara de Tilcara; 20) El Alfarcito.

del sitio existe un espacio despejado de superficie casi plana de $2400 \mathrm{~m}^{2}$, que si bien puede no contar con todas las propiedades que se conocen para una aukaipata en el Collasuyu (Raffino y Alvis 1993), no deja de ser un espacio creado y modificado bajo el poder imperial. Se considera que La Huerta, junto con las instalaciones agrícolas de Coctaca al norte de la quebrada troncal, es el sitio de la región que sufrió los mayores cambios arquitectónicos impulsados desde Cusco (Raffino 1993a). Sin embargo, debemos aclarar que no se ha analizado exhaustivamente cuál fue la manera en que se remodeló el sitio bajo la ocupación incaica, como tampoco se ha profundizado en el aspecto que tenía antes de la ocupación estatal, es decir, se desconoce si existieron sectores con arquitectura local arrasados o parcialmente reutilizados por los incas al momento de construir sus estructuras.

Palma (1996) divide a La Huerta en tres sectores (Figura 3). El sector B correspondería al inicio de la ocupación, datado radiocarbónicamente en $c a$. 800 DC (Raffino y Alvis 1993), con conjuntos de edificios relacionados a los momentos preincaicos, y estando activo hasta la conquista. El sector C, de acuerdo a los fechados obtenidos en su basural más cercano (PS2), ${ }^{2}$ sería contemporáneo a la ocupación

\footnotetext{
2 PS2: Pozo de sondeo 2 (Figura 3). Excavaciones realizadas en el basural ubicado entre los sectores $\mathrm{A}$ y $\mathrm{C}$ de donde se obtuvieron las muestras fechadas.
} 


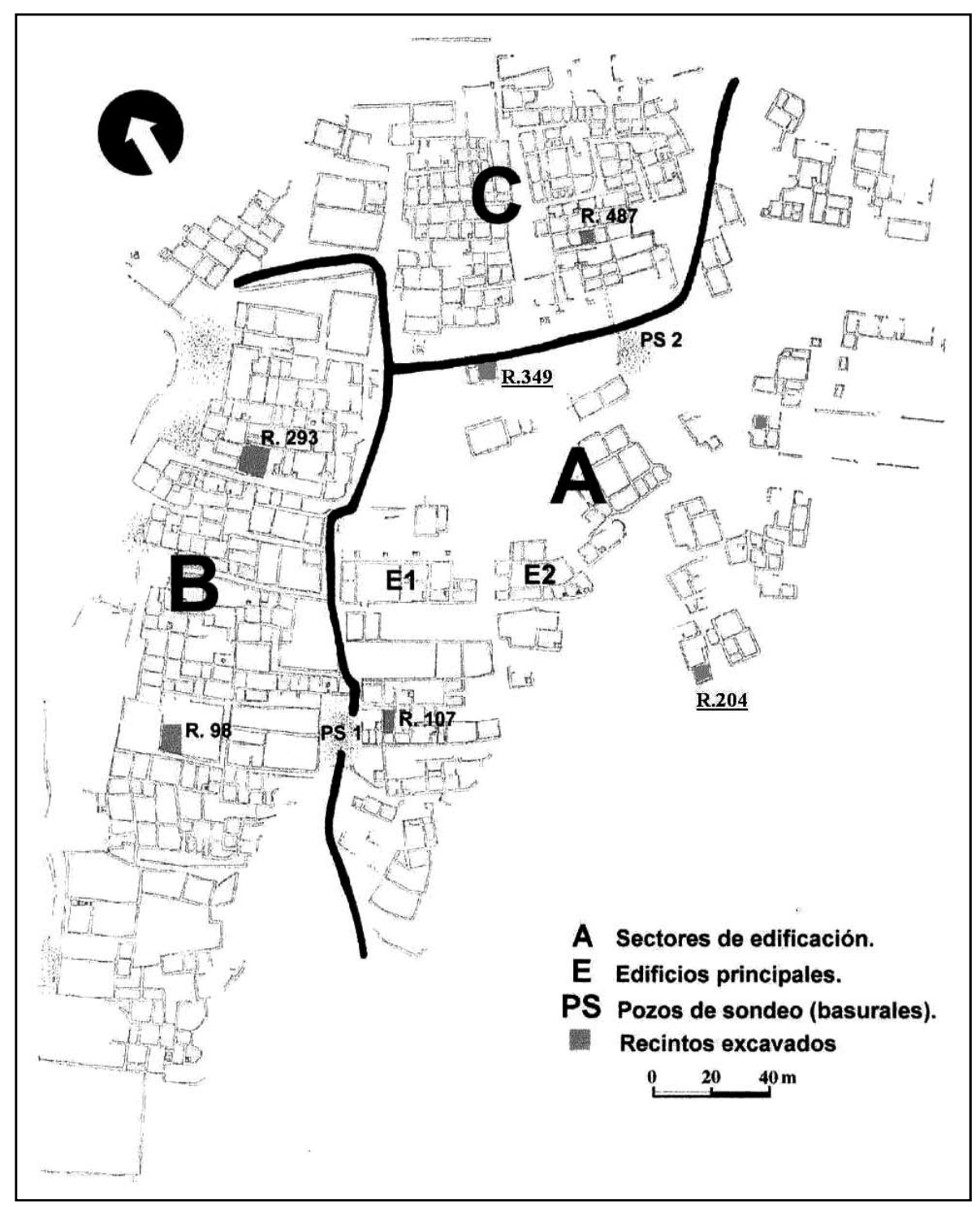

Figura 3. Planta urbana de La Huerta; división en sectores.

incaica. Se encuentra atravesado por el camino imperial y fue la disposición de las estructuras y la cerámica altiplánica recolectada en superficie las que hicieron a Raffino y colaboradores (Raffino 1993b) sospechar que el sector fue producto de la instalación de mitimaes altiplánicos. Finalmente, el sector A está íntimamente relacionado con la presencia incaica. Cuenta con dos edificios principales que cubren 1440 de los $7227 \mathrm{~m}^{2}$ ocupados por recintos: el Edificio 1 se conforma por 12 recintos y una superficie de $640 \mathrm{~m}^{2}$ más una explanada, el recinto 582 de $350 \mathrm{~m}^{2}$ (Raffino y Alvis 1993); y el Edificio 2, con $450 \mathrm{~m}^{2}$ de superficie, no presenta atributos arquitectónicos estatales a excepción de su planta estructural. Asimismo, en este sector, particularmente en el Edificio 2, se han hallado las tumbas con la más rica parafernalia, las cuales fueron excavadas tempranamente por Debenedetti (1918). Allí se encontraron piezas como vinchas de plata y gran cantidad de instrumental textil. Es a partir de esto que se adjudica la ocupación de este edificio a alguna autoridad local promovida por el Imperio y a artesanos textiles o cumbicamayoc (Raffino y Alvis 1993: 70).

Es en este sector del sitio donde se encuentra la mayor cantidad de elementos diagnósticos de la arquitectura incaica, como grandes jambas en los accesos, muros 
dobles con refuerzo de banqueta, piedras canteadas y escalinatas de piedra (Figuras 4 y 5). Estos rasgos fueron reconocidos tempranamente por Lafón (1956) como la presencia de algún reflejo extraño del Imperio. Es necesario destacar que el autor lo veía no como una acción directa del Tawantinsuyu, sino como la acción de otro pueblo, probablemente altiplánico, influenciado por los incas.

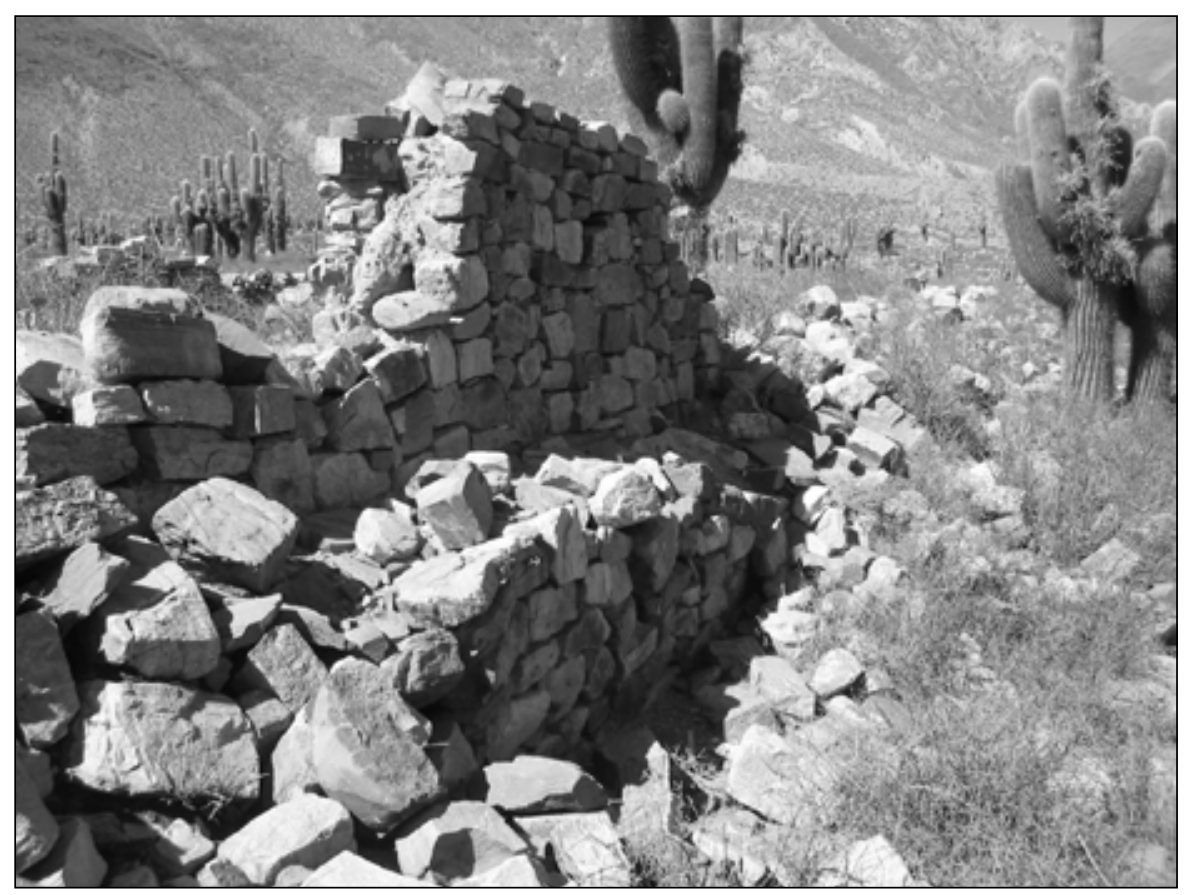

Figura 4. Arquitectura incaica en La Huerta.

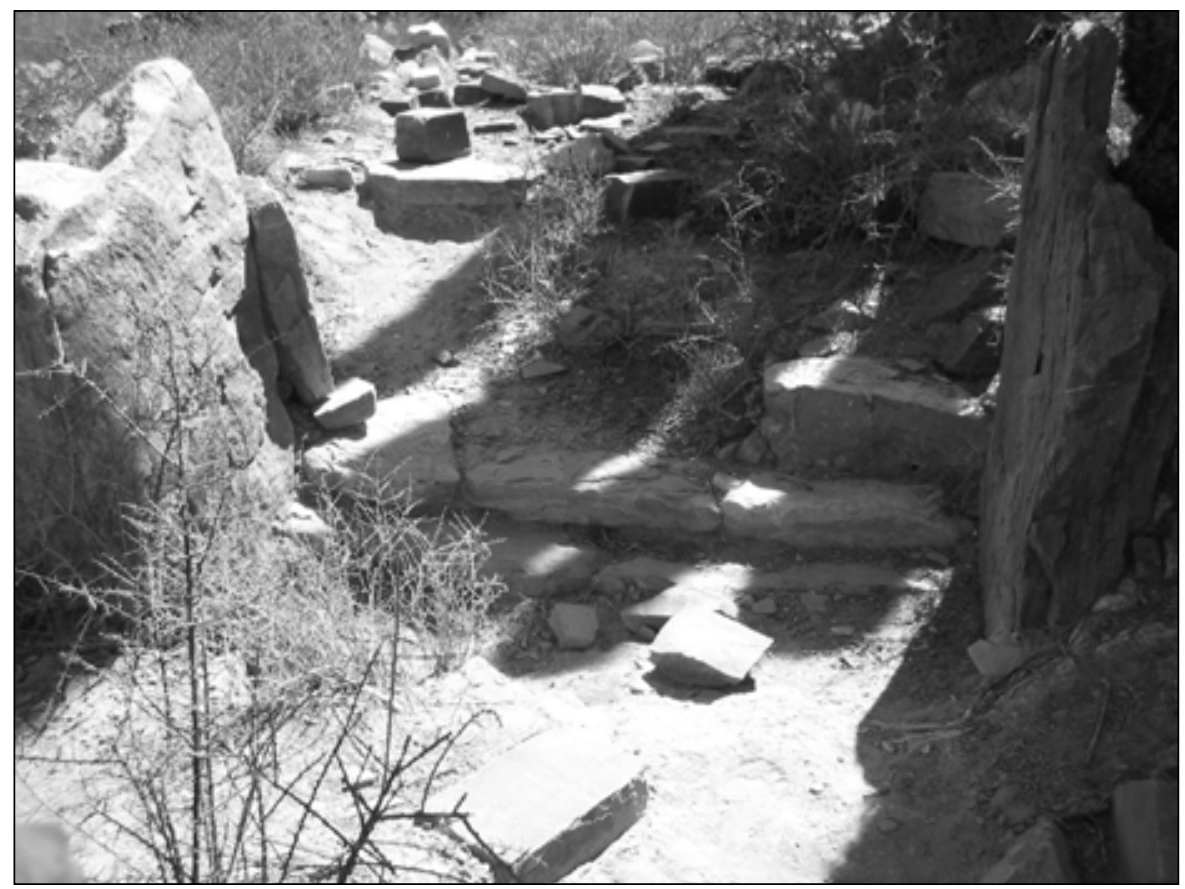

Figura 5. Jambas y escalinata en el Edificio 1. 


\section{Metodología y análisis de la espacialidad en La Huerta}

Hasta el momento, la mayoría de los análisis arquitectónicos que se han llevado a cabo en el sitio han sido casi totalmente técnicos, yendo desde la medición de los recintos y el levantamiento de planos (Raffino y Alvis 1993) hasta el análisis de las características formales del diseño de la arquitectura (Fernández Do Río 2001). Este último se ha basado en las variables propuestas por Moore (1996): escala, permanencia, centralidad, visibilidad y accesibilidad. En su análisis, Fernández Do Río destaca la gran escala, visibilidad pública y alta permanencia de la plaza, así como su ubicación central dentro del área intramuros. Asimismo, aplica en sus investigaciones acerca del registro arquitectónico de los sitios La Huerta y Campo Morado los análisis gamma de Hillier y Hanson (1984) a la hora de observar patrones de acceso y la estructuración social del espacio. Es a partir de estos antecedentes que visualizamos la arquitectura de La Huerta desde otra perspectiva, poniendo énfasis en el espacio que las construcciones generan, considerándolo como la realidad en que se concreta la arquitectura (Zevi 1951). Deseamos alejarnos, en la medida de lo posible, de un acercamiento meramente funcional de la arquitectura y el espacio, de remitirnos a la elaboración de tipologías descriptivas. Por el contrario, pretendemos analizar la producción del espacio históricamente, observando cómo las luchas por el poder se imprimen en el planeamiento, diseño, construcción y uso, así como en la demolición o destrucción de los edificios (Hayden 1997: 123).

Con este objetivo en mente abordamos la espacialidad de La Huerta a partir del análisis de las propiedades visuales de las estructuras y su distribución espacial. Consideramos que a través de la arquitectura y la espacialidad se producen, manifiestan y reproducen relaciones de poder. La manipulación del espacio es un mecanismo de dominación y control social, así como un medio transmisor de la ideología dominante. $\mathrm{La}$ arquitectura condiciona las relaciones entre las personas, les indica por dónde circular, hasta dónde pueden acceder y qué pueden o no observar. Se convierte, de esta manera, en una expresión física de las divisiones sociales (Moore 1996), en una tecnología de poder (Foucault 1976) que disciplina los cuerpos y exige su distribución en el espacio. Así, la arquitectura no solo crea cosas materiales como casas y edificios, sino también significados (Thomas 2001: 179).
Creemos que los edificios son testimonios físicos del uso del poder y, como constructos culturales, están imbuidos de significados, a la vez que contienen información asociada a las relaciones de dominación y poder (Moore 1996). Son símbolos que condensan experiencias sociales y políticas colectivas.

Las propiedades visuales de las estructuras generan segmentación y diferenciación social. Estas excluyen a determinada gente de cierto tipo de actividades, al mismo tiempo que las estructuras en sí mismas causan un impacto sobre la percepción que las personas tienen sobre el paisaje. La visibilidad puede ser entonces manipulada, se pueden obstruir o bien destacar determinados puntos del paisaje en la persecución de ciertos fines políticos. A su vez, la percepción del observador depende de la posición que éste ocupa en el espacio; diferentes ángulos o distancias darán una percepción distinta. Es por eso que esa posición de observación y el acceso que las personas tengan a ella generará distintos modos de acercarse al espacio socialmente construido. Por otro lado, es una manera de limitar las acciones tanto económicas como políticas de un grupo, al constreñir su reproducción social limitando el acceso a ciertos espacios (Hayden 1997). De esta manera, el control de la visión y los límites impuestos en el espacio se constituyen en mecanismos de dominación.

Asimismo, pretendemos acercarnos al espacio y al paisaje de un modo alejado del cartesianismo que ha dominado estos análisis, dejando a un lado análisis sólo basados en mapas, los cuales proporcionan un instrumento para hacer el mundo maleable, manipulándolo al tiempo que deshumanizándolo (Thomas 2001: 170), viendo el espacio limpio y ascético, como un sitio donde no existe el poder, el conflicto, las emociones. Intentaremos entonces humanizar ese paisaje, imaginarlo con gente viviendo en él, entender la forma en que ésta se conducía en ese espacio tridimensional, experimentándolo y percibiéndolo. Siguiendo a Thomas acordamos que:

“...no podemos 'conseguir llegar' al significado del pasado, y ciertamente, no podemos meternos en la cabeza de las personas del pasado mediante actos de empatía, pero podemos ponernos dentro del conjunto de circunstancias materiales que se integraban en un universo significativo en el pasado" (2001: 180-181). ${ }^{3}$

Traducción de J. L. García Valdivia y L. García Sanjuán. 


\section{Diferencias en la distribución espacial}

Observando el plano de La Huerta podemos notar que el diseño espacial del sector incaico o A muestra importantes diferencias con el resto de los sectores del sitio. Estas distinciones se vuelven mucho más vívidas y notables al atravesar y recorrer el sitio en medio de las derruidas estructuras. Si bien las construcciones en el sector B pueden catalogarse como de buena calidad, con paredes resistentes e incluso muros dobles, debemos destacar que esta calidad es sensiblemente superior en el sector incaico.

Una de las diferencias más significativas y dignas de mencionar es la evidente menor aglomeración de recintos que existe en el sector A con relación al enmarañado sector B. Esta se hace más notoria principalmente en la zona ubicada al este de los edificios 1 y 2, cruzando la cárcava que atraviesa el sitio. Allí encontramos espacios más abiertos entre grupos de, por lo general, tres, cuatro o cinco recintos. Se trata de un espacio más amplio, menos cargado que el de los sectores $\mathrm{B}$ y $\mathrm{C}$ donde los recintos se encuentran en un conglomerado, sin esta clase de espacios entre sí.

Si bien el sector B cuenta con varias vías de circulación que lo atraviesan en sentido este-oeste, acceder a alguno de los recintos que no se encuentran directamente asociados a una de estas vías debió significar, por lo menos, tener que atravesar recintos o bien caminar sobre los muros. Esta misma situación se puede observar en el sector $\mathrm{C}$, el cual es atravesado por el Camino Inca.

Esta forma de llegar a los recintos, sumada a la siempre cercana vecindad con los recintos contiguos, permitía ver, escuchar, e incluso oler de una manera más directa lo que sucedía en su interior. Esta situación generaba una falta de privacidad y un sinfín de, voluntarias o no, experiencias compartidas que difícilmente se daban entre las personas que habitaban los grupos de estructuras del sector A, situados al otro lado de la cárcava. La vida cotidiana en este sector adquiere un matiz mucho más público, donde las actividades desarrolladas por aquellos que vivían aquí no se ocultan ni presentan misterios para sus vecinos. Esas actividades pueden ser cocinar, elaborar vasijas cerámicas, o eventos ceremoniales o rituales como enterrar a los difuntos en los mismos recintos.

Por otra parte, con este modo de vivir surgen nuevos problemas. Al interior de los conglomerados del
Tardío se evidencian el hacinamiento y condiciones higiénicas deterioradas (Nielsen 1996). A esta situación se suma el crecimiento de la población y, por consiguiente, el de las inhumaciones en los pisos de las casas que tornarían dramática la disponibilidad de espacio (Palma 1998).

Las construcciones incaicas ubicadas en el este del sector A, a las que se le suma el Edificio 1, poseen la mayor calidad constructiva de todo el sitio. Cuentan con las piedras más finamente canteadas y en muchas oportunidades alcanzan un alto grado de conservación, como lo prueba la baja degradación de algunos muros, como los del Edificio 1 (Figura 6), los cuales tienen alturas superiores a $2 \mathrm{~m}$. Un buen ejemplo de este tipo de recintos es el R204 (Figura 7). Situado sobre una de las laderas del sitio, prácticamente asomando al vacío, es uno de los más claros exponentes de la fina arquitectura incaica en La Huerta. Cuenta con muros dobles compuestos por piedras de excelente canteado unidas con mortero, y en el muro este destaca la presencia de un hastial. En este recinto, ubicado en una zona algo apartada, lindero solo a otra estructura, hay también arquitectura funeraria de una calidad constructiva notable (Jacob y Leibowicz $2005 \mathrm{Ms}$ ). El acceso a distintos recursos y cultura material incaica que tuvieron los habitantes de este recinto es mostrado por algunos hallazgos, entre los que se destacan piezas metálicas como aros y un tumi confeccionados en una aleación de bronce estañífero y una lámina producto de una aleación de oro y plata; fragmentos de piezas cerámicas tales como aribaloides, recipientes elaborados en cucurbitáceas pintados en su exterior con pigmentos rojizos, diversos artefactos de madera y múltiples componentes del universo textil (Jacob y Leibowicz $2005 \mathrm{Ms}$ ). Es importante mencionar que el sector donde se ubica esta estructura no es alcanzado por las principales vías de circulación del sitio, es decir, no es accesible desde el Camino Inca, el cual conduce a quien llega al sitio por medio del sector B, la zona de la plaza y el sector $\mathrm{C}$, siempre a una importante distancia de este conjunto arquitectónico.

Considerando las características mencionadas para esta estructura, la sensación de privacidad que debieron experimentar sus habitantes hubiera sido imposible de reproducir en los recintos habitables del sector donde predomina la arquitectura local así como en el sector C, adscrito hasta hoy a la ocupación de posibles mitimaes altiplánicos. Las actividades de toda índole que se realizaban en este tipo de recintos no tuvieron por qué ser públicas o fácilmente 


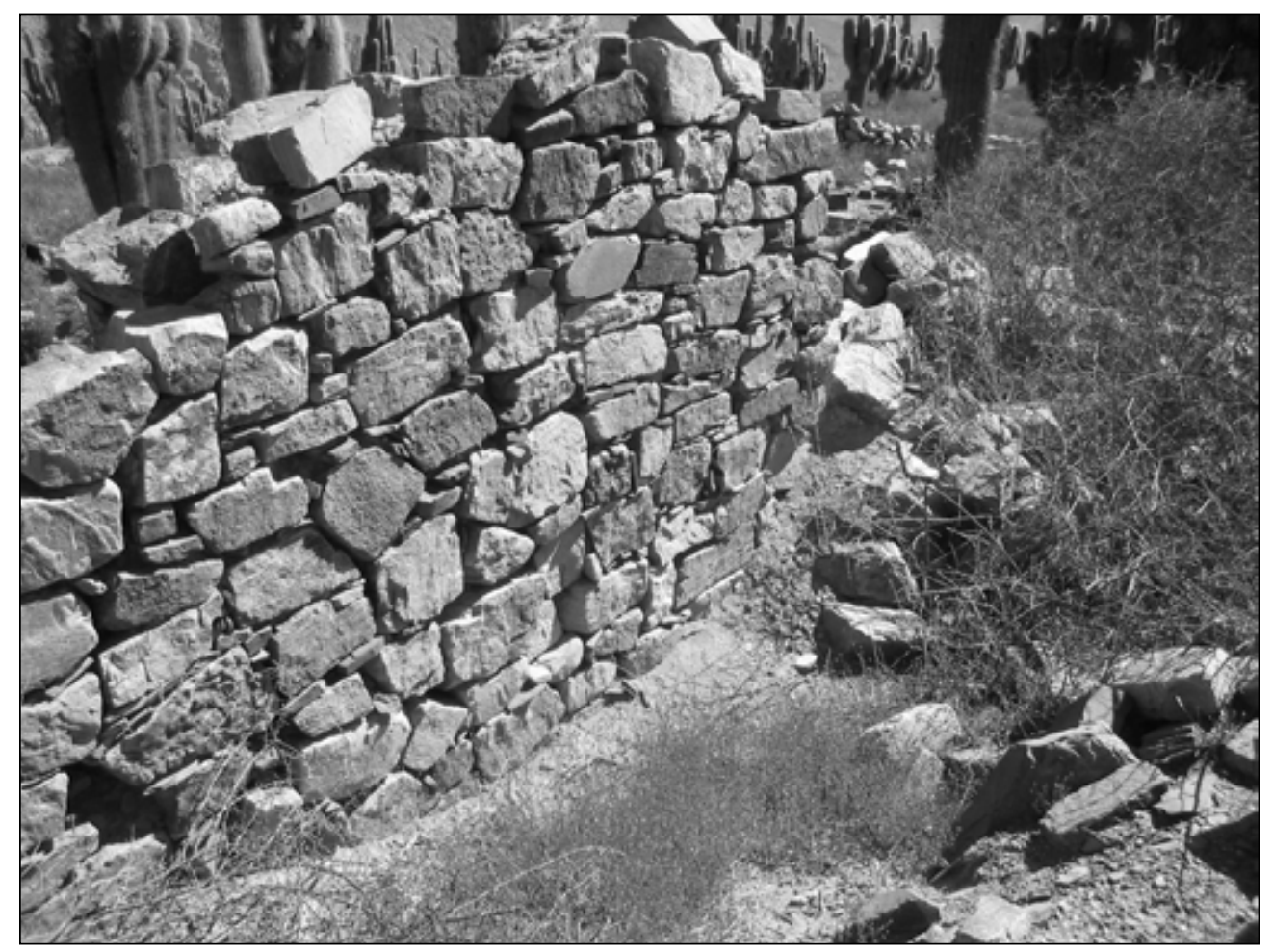

Figura 6. Edificio 1.

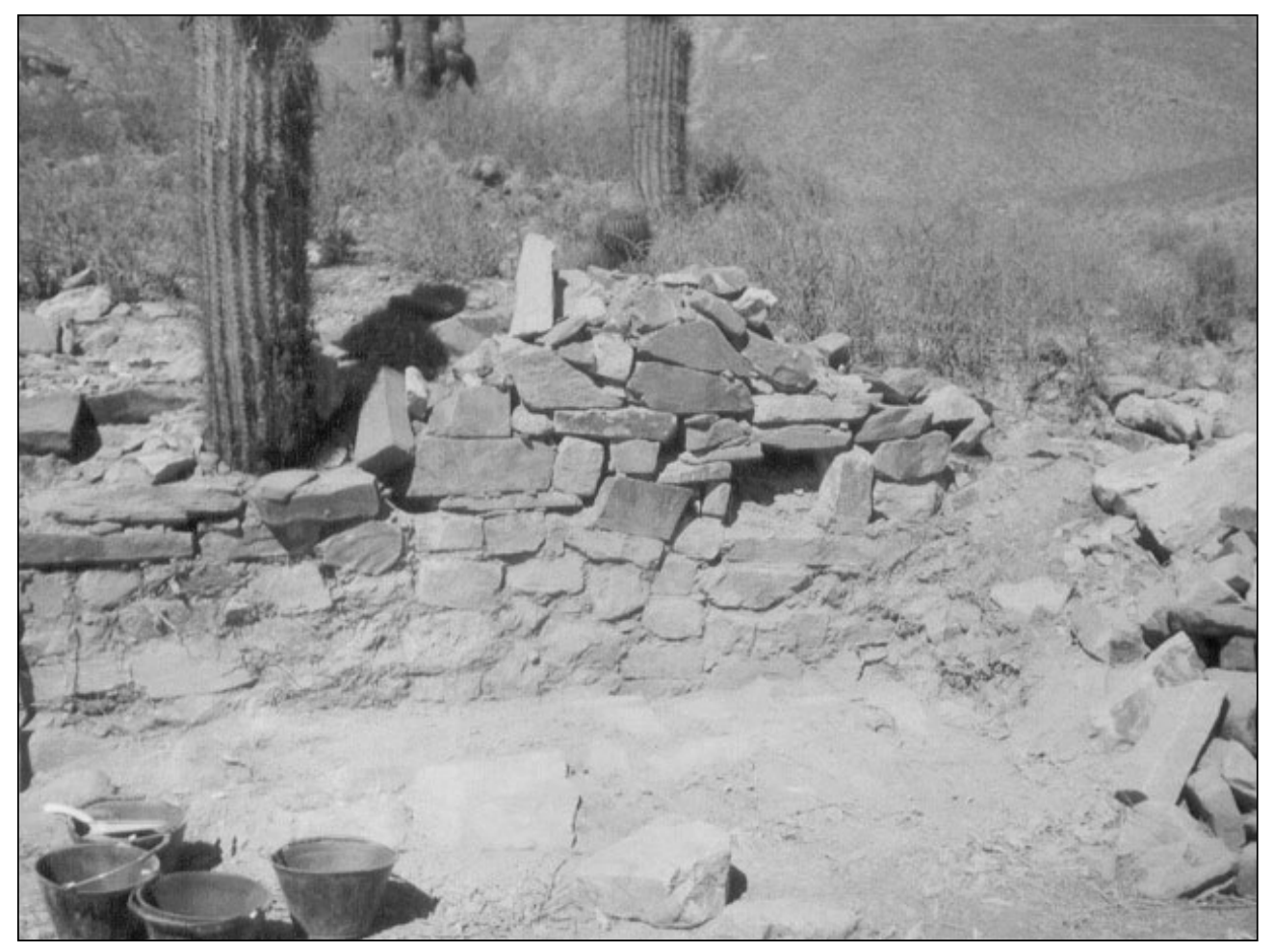

Figura 7. Recinto 204, antes de comenzar las excavaciones. 
accesibles a sus vecinos. El ritual de enterrar a un familiar o la producción de cualquier tipo de bienes, por ejemplo, era posible de efectuarse en un ambiente privado. Aquí sí se podían llevar a cabo acciones que no implicaran el conocimiento generalizado de las mismas, ni conllevaran el compartir experiencias con aquellos que habitaban en las cercanías.

La experiencia social de los individuos en el espacio debió, sin lugar a dudas, ser muy distinta en el sector incaico de como lo fue en los sectores B y C. El Imperio en su afán por imponer su poder político transformó y modificó múltiples aspectos de la vida en La Huerta. Al cambiar la distribución espacial del sitio pervierte el orden del Tardío, imponiendo un nuevo modo de vida, de entender y experimentar el espacio, lo que creemos, se encuentra relacionado a jerarquías y relaciones sociales hasta entonces inéditas en la región.

\section{División entre el mundo inca y no inca}

Otro punto del análisis que pretendemos desarrollar es la división que se produjo a nivel espacial entre el sector incaico y en el local. Desde su llegada a La Huerta los incas produjeron importantes cambios, con lo que construyeron un nuevo paisaje en el interior del poblado. En este proceso de construcción generaron una brecha social con la población local, reforzando su superioridad, creando y a la vez legitimando su dominio.

La división entre estas dos esferas se manifiesta de diversas maneras, algunas más tajantes y evidentes, con una fuerte presencia física, mientras que otras se dan de un modo más sutil, sin que esto conlleve implícitamente una menor efectividad. Esta separación es articulada en algunos sectores del sitio por el Camino Inca. Es digna de mencionar la importancia que los caminos tenían dentro de la concepción incaica del espacio, como símbolos de la expansión imperial. El Camino Inca atraviesa el sitio en una sucesión de segmentos rectos y quebrados, limitados por las construcciones habitacionales, comunicándose con los edificios incaicos y la plaza (Raffino y Alvis 1993).

El qhapaqñan (Figura 8) ingresa al asentamiento desde la quebrada de La Huerta por el gran recinto 1 , bordeando el sitio por el oeste, sobre la ladera que da al río Sisilera. Luego, el camino cambia su rumbo hacia el este, a la altura del Edificio 1, hasta las jambas de acceso al sector incaico. Posteriormente, atraviesa la plaza por el oeste y luego se bifurca a la hora de atravesar el sector-C. Raffino (1988) considera que el hecho de que el Camino Inca

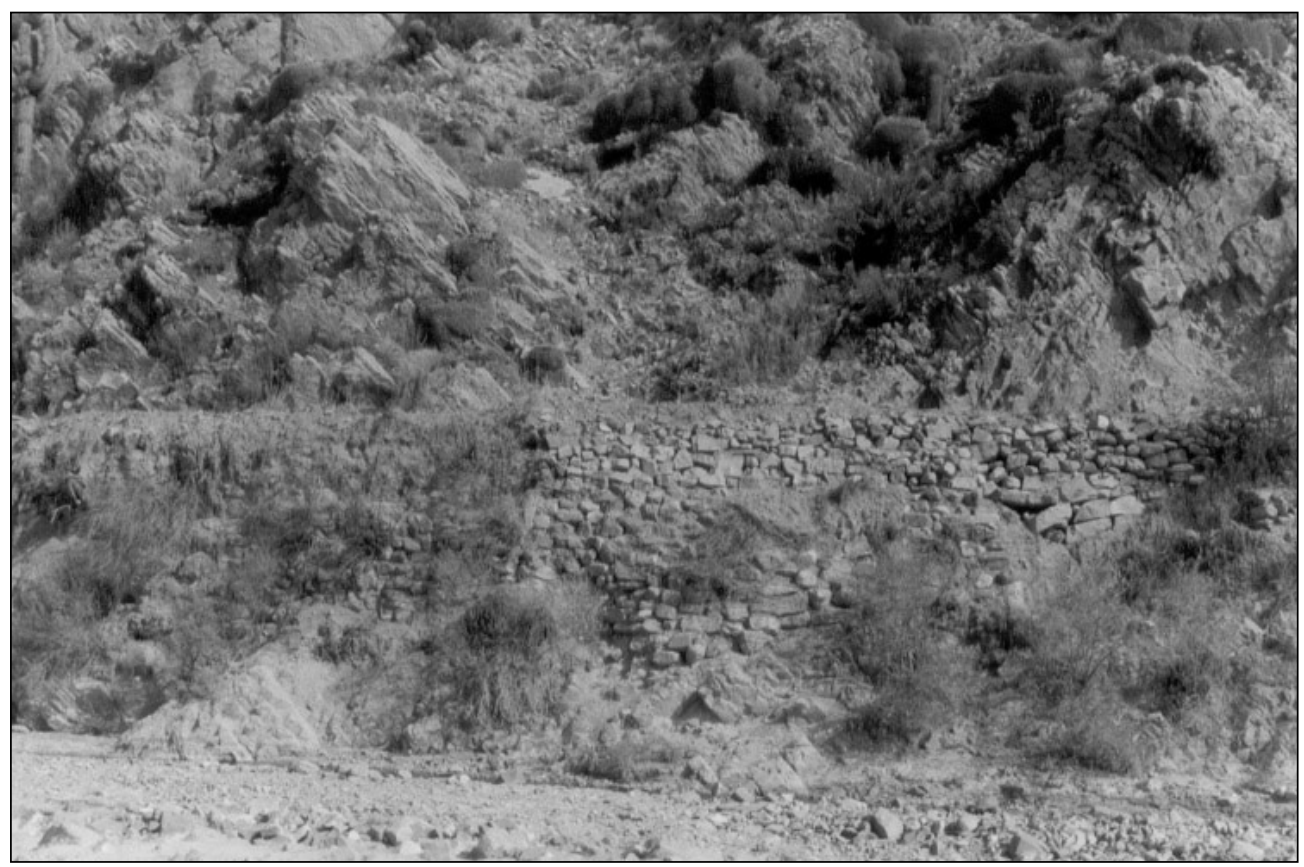

Figura 8. Tramo del Camino Inca frente a La Huerta. 
atraviese el sitio, a pesar del mayor costo y trabajo que esto implica, da cuenta de la importancia que tuvo La Huerta en esos momentos.

Otro sector del Camino Inca a intramuros de $\mathrm{La}$ Huerta divide los sectores A y B, desde las mencionadas jambas, hasta el principal basural del sitio. A partir de las jambas un muro que no presenta evidencia de haber alcanzado gran altura continúa la separación hasta llegar a la plaza (Figura 9). A partir de aquí, paralelo a las paredes este de los recintos 299, 312, 321, 336 y 337, y a una distancia de alrededor $1.5 \mathrm{~m}$, se levanta un muro que corre paralelo a la plaza. Este debió contar con una altura considerable en su momento de esplendor, y tiene un ancho de más de $1 \mathrm{~m}$, alcanzando a cubrir el costado oeste de la plaza en su totalidad. Podemos observar cómo esta pared divide visual

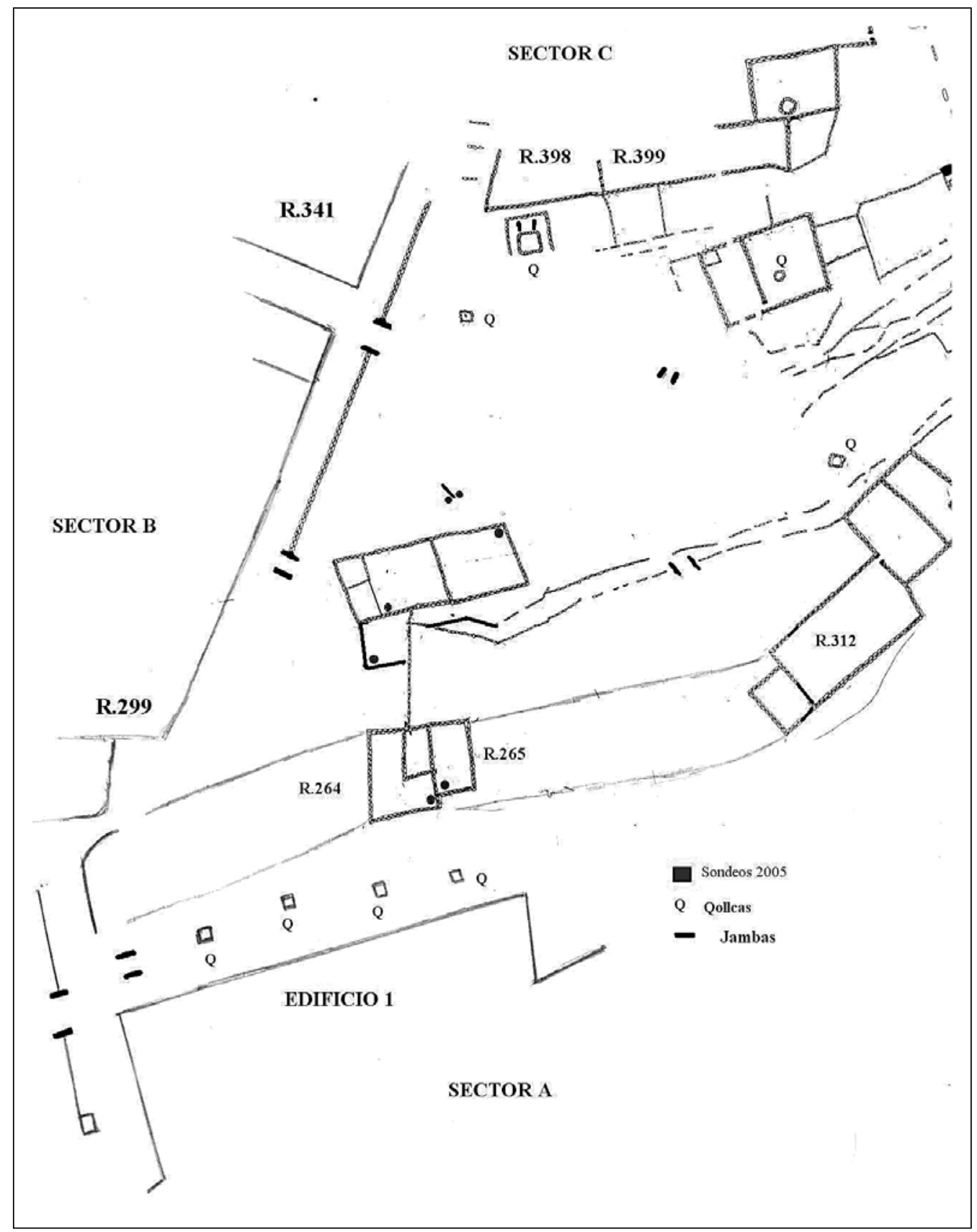

Figura 9. Plano del sector de la plaza, donde se destacan las jambas y collcas presentes así como los últimos sondeos realizados. 
y materialmente al sector B de un espacio público de vital importancia dentro del sector estatal. Por otra parte, en la zona norte del sector B, un muro lo divide de un grupo de estructuras que se asemejan bastante tanto en factura como en distribución espacial a las que encontramos en el sector A, antes que a sus vecinas del sector $\mathrm{C}$.

Encontramos en este sector ocupado por la posible plaza gran cantidad de rocas enormes o jambas de diversos colores (p.e., amarillo, rosa y verde) que aparecen como importantes referencias dentro del paisaje del sitio. Estas fueron colocadas intencionalmente en los bordes del sector despejado, delimitándolo, o en el caso de las que se encuentran de a dos, marcando el ingreso al mismo. La incorporación de rocas tal y como se las encuentra en la naturaleza es una de las características de la arquitectura incaica.

El control de la visión sobre estos espacios públicos, así como del acceso a los mismos se torna evidente en La Huerta. En primer lugar, el ingreso al mundo incaico desde el sector local está mediatizado por dos grandes jambas, las mayores del sitio, y son de una llamativa roca color rosa. Desde este ingreso, al norte del Edificio 1, se accede a una serie de cuatro collcas alineadas paralelamente a uno de sus muros para desembocar directamente en la plaza. A su vez, el acceso al recinto 582, un gran patio interno dentro del Edificio 1, se encuentra delimitado también por jambas y cuenta con una pequeña escalinata. Este es, al igual que la plaza, un lugar ideal para reunir una significativa cantidad de gente y realizar ceremonias. Estas podrían haber revestido, debido a su restringido y para nada sencillo y público acceso, un carácter tal vez más reservado o privado.

Es en espacios abiertos como los últimos que hemos mencionado donde el Tawantinsuyu llevaba a cabo toda clase de ceremonias y rituales. Este tipo de eventos y prácticas, donde se desplegaban recursos teatrales y que contaban con una gran espectacularidad, era una característica clave de los incas en sus conquistas provinciales. Los incas estaban, de este modo, relacionados con el control de los sectores públicos y, por lo tanto, al control del ceremonial y el ritual. Esto es muy importante teniendo en cuenta que en los Andes lo cognitivo e ideológico está explícitamente incorporado en las esferas económicas y sociales, donde la actividad ritual tiene implicancias económicas, y lo ceremonial se articula con lo material (Henderson y Netherly 1993 cit. en Uribe 2004).

El Tawantinsuyu adquiere un control total del ceremonial público donde despliega toda su parafernalia simbólica. En estas ceremonias se reproducían y legitimaban concepciones religiosas y sociales que solidificaban el poder estatal. A través de estas performances rituales los espacios públicos adquirían significados y asociación con determinada simbología. En estas ceremonias, poderosos significados asociados a espacios físicos son creados y activados (Lawrence y Low 1990).

En las ceremonias que se habrían desarrollado en la plaza de La Huerta, las personas que habitaban fuera del sector central incaico solo pudieron acceder con el consentimiento de aquellos que ostentaban el control político. Este espacio donde se representaban principios fundamentales en la reproducción de la vida andina se encontraba restringido tanto en su acceso como en su visibilidad para aquellos que se encontraban fuera de la esfera incaica.

El Imperio se relaciona con los aspectos sagrados y religiosos de la vida andina. Se apropia de espacios, mitos, leyendas, y se transforma en el nexo entre las sociedades conquistadas y las divinidades. Se hace parte de la historia de los conquistados, situándose en un lugar sagrado o divino. El nuevo orden se hace patente y se reproduce en las ceremonias donde los incas aparecen relacionados con las fuerzas sobrenaturales.

En La Huerta la instalación del sector público incaico se realiza en un lugar vecino al que era originalmente habitado por la población local. Esta vecindad no hace más que reforzar la imagen de superioridad del Estado, ya que se instala contiguamente pero remarcando de un modo explícito las diferencias que existen entre ambos mundos. Mediante una arquitectura de una escala superior a la conocida, nuevas formas de concebir el espacio y la imposición de límites visuales y de acceso, se realza el dominio político, social y religioso del Tawantinsuyu. Este tipo de división entre sectores propios de conquistadores y conquistados es evidente en distintos lugares del Imperio. Una de las más impresionantes es la que se da en Chagua o Maucallajta, en el altiplano del sur de Bolivia, donde la arquitectura cusqueña, de pirca bien trabajada, se encuentra mucho mejor conservada que la local y donde: 
“...una muralla baja divide el área intramuros en dos sectores claramente definidos. A partir de esa muralla, comienza la arquitectura cusqueña, la cual se diferencia ostensiblemente de las estructuras locales o chichas" (Raffino 1993c: 178).

Como hemos argumentado, fundamentalmente lo que hizo el Imperio Inca fue resignificar y reestructurar la espacialidad del sitio, modificando el espacio socialmente construido y las experiencias de la gente en él, al tiempo que promovía la imposición de su ideología como medio de dominación y control.

\section{El Edificio 1 como símbolo del poder imperial}

El Edificio 1 (Figuras 10 y 11) es el máximo exponente de la arquitectura desarrollada por el Tawantinsuyu en La Huerta. Representa un caso único en toda la quebrada de Humahuaca, ya que su tamaño y forma no encuentran ninguna similitud o equivalencia en los sitios con ocupación incaica en la zona. Su alta calidad constructiva sólo es comparable con otros recintos del sector incaico que poseen la mejor arquitectura del sitio (p.e., R204), los cuales se encuentran al este, al otro lado de la cárcava que lo atraviesa.

Además, este edificio se ubica prácticamente en el centro del poblado. Esta característica, sumada a su tamaño y altas paredes, le otorga la particularidad de poder ser observado a la distancia desde los distintos sectores del sitio, incluidos aquellos no incaicos (B y C):

"Observando desde la parte sur son visibles las intenciones escenográficas, consumadas mediante la elevación artificial de todo el cuerpo y realzadas por la imponencia de las jambas que limitan el vano de acceso" (Raffino y Alvis 1993: 69).

Esta clase de edificios públicos, construidos bajo la dirección de los administradores del poder imperial, exhibían, testimoniaban y difundían los valores e ideas sostenidos por el Tawantinsuyu, cuyos significados debían ser comprendidos por la sociedad en su conjunto (Moore 1996). Los pobladores locales de La Huerta, y de la región en general, debieron ser de alguna forma reeducados o resocializados, en pos de la comprensión de estos nuevos símbolos, de esta nueva espacialidad (Acuto 1999a).

Podemos afirmar entonces que una construcción de esta magnitud debió impactar de gran modo y a diferentes niveles las percepciones que los pobladores preincaicos del sitio tenían sobre el lugar que habitaban. Estas personas se movían dentro de un paisaje bastante homogéneo, en un contexto de recintos similares en el que ninguno sobresalía por su tamaño y donde no

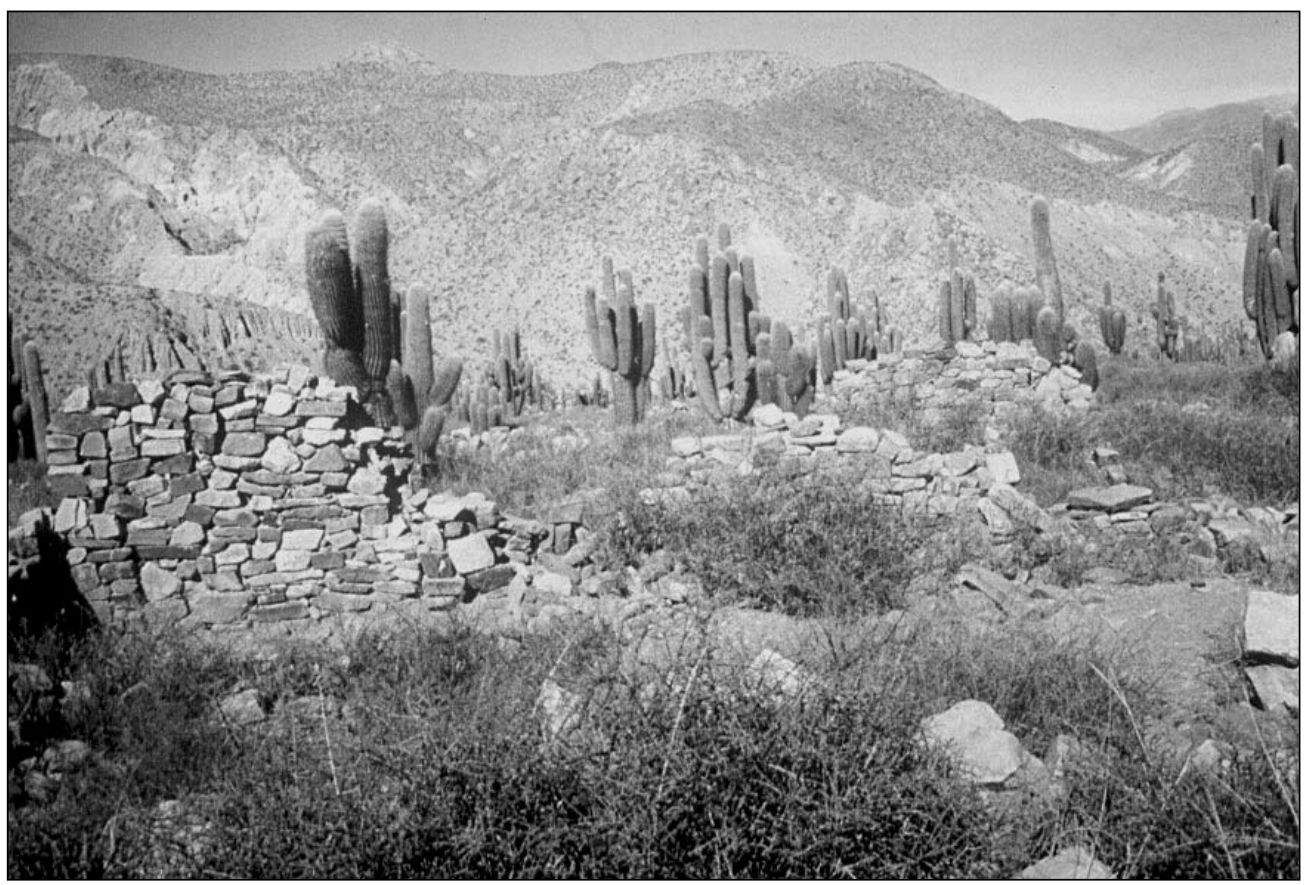

Figura 10. Edificio 1, visto desde el norte. 


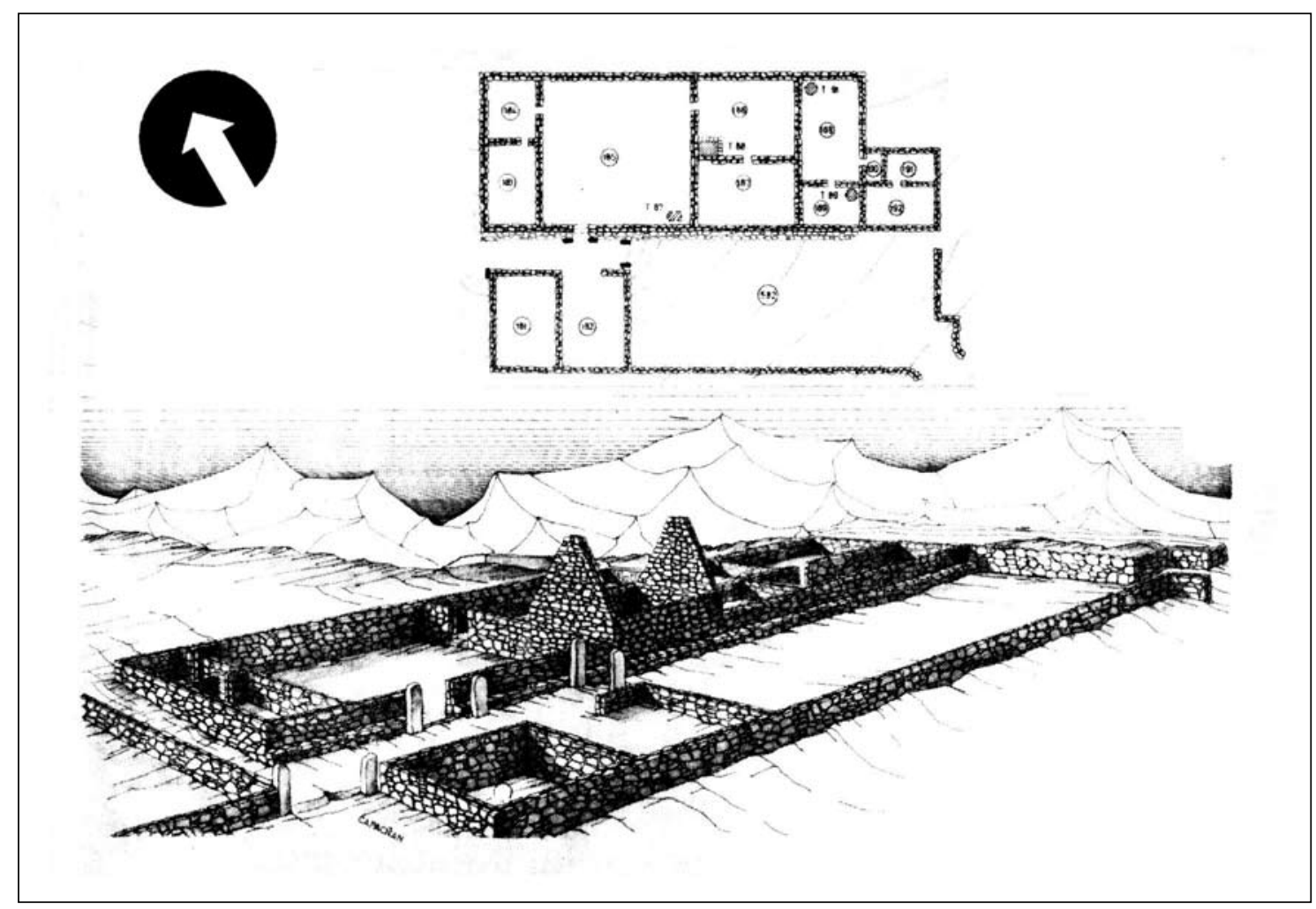

Figura 11. Edificio 1. Vista en planta y en tres dimensiones. Tomado de Raffino y Alvis (1993).

había diferencias internas destacables, ni arquitectura de gran escala o pública. Estos grupos sociales, ahora viviendo bajo el dominio de un nuevo poder, se encontraron con una imponente y novedosa estructura que modificaba largamente su visión y percepción sobre ese espacio. Y no nos referimos únicamente al impacto que tal estructura pudo haber tenido desde un punto de vista arquitectónico, sino a los significados que esta conllevaba, a las relaciones sociales que representaba y reproducía. El sitio donde esta gente había nacido y vivido cambiaba drásticamente de aspecto, los lugares familiares contaban ahora con significados radicalmente distintos y dejaban de ser accesibles cotidianamente.

Las ideas que los incas traían consigo, las nuevas relaciones sociales, políticas y económicas que promovían, su cosmología, se imponían sobre la población local y comenzaban a aparecer como naturales. Vemos de esta manera que con la reestructuración espacial del sitio, los cambios en la experiencia social de los individuos en el espacio cobran un papel fundamental, reproduciendo a la vez que produciendo nuevas relaciones sociales y espacialidades. Prácticas sociales vinculadas al poder e ideología imperiales obtienen su correlato material en estos nuevos espacios rituales y edificaciones.

\section{Discusión}

Lo que hemos expuesto nos lleva a repensar la situación de La Huerta antes de la ocupación incaica. La visión tradicional del sitio es la de una cabecera regional que controlaba las tierras productivas de la quebrada troncal y las laterales, un polo de poder que ejercía algún tipo de control político sobre los sitios más pequeños (Palma 1998). Esto ocurría en el marco del Período Tardío marcado por una competencia entre sitios y una situación de conflicto bélico endémico producto de un importante crecimiento demográfico y de la competencia por bienes de subsistencia (Nielsen 1996; Palma 1998, 2000). Esta postura sugiere que durante dicho período se habría dado en la quebrada de Humahuaca una creciente estratificación social y situaciones de competencia por liderazgos (Palma 2000) y se basa en varios y diferentes estudios que se centran en la existencia de jerarquías entre sitios (Palma 1991, 1998; Albeck 1992), en análisis de rangos en la funebria (Palma 1993) y de explotación económica 
(Olivera y Palma 1986; Nielsen 1988, 1989; Albeck 1992). No obstante, la única evidencia de arquitectura de relevancia pública del Período Tardío en la región sería el llamado Complejo A de Los Amarillos (Nielsen 1995b). Por su parte, el sector B de La Huerta, de predominante arquitectura local y el cual habría sido habitado durante todo el lapso temporal de ocupación del sitio, cuenta entre sus características relevantes una escasa complejidad estructural, un alto grado de conexión intrasector, con ocupantes sin un estatus especial, realizando actividades cotidianas y enmarcados en una estructura social no estratificada (Fernández Do Río 2001). A su vez, no hay evidencia en los diversos sectores excavados de que recintos preincaicos hayan sido arrasados o demolidos para construir sobre ellos las principales instalaciones imperiales del sitio. Tampoco hay evidencia de ocupaciones anteriores en el sector A o inca (Leibowicz 2006 Ms). Es decir, a pesar de las excavaciones realizadas, no podemos aún tener una imagen fehaciente de $\mathrm{La}$ Huerta preincaica.

Por lo tanto, entendemos que el sitio durante los Desarrollos Regionales debió tener como máxima extensión la adjudicada al sector B en la actualidad. De esta manera, no contamos para el Período Tardío en La Huerta con evidencia de segregación social o jerarquías a nivel tanto espacial como arquitectónico (p.e., edificios destacados, plazas). Tampoco hay en este sector evidencia de tumbas jerarquizadas (Palma 1993), lo que estaría apoyando la visión que entregan la arquitectura y el análisis del resto de la cultura material respecto a que en el sector B no hay diferenciación interna entre una élite y gente del común. Por su parte, aunque Nielsen (1996) menciona la existencia de bienes rituales o de prestigio durante la Fase Pukara de su cronología, la cual corresponde al final del Período Tardío (1360-1430 DC), no deja de destacar su baja ubicuidad. Asimismo, en Juella, otro gran sitio de la región para el Período Tardío, se destaca la homogeneidad en los ambientes domésticos y el registro arqueológico (Nielsen et al. 2004). Una situación similar ocurre en el sitio Keta Kara o San José, ocupado sólo en el Período Tardío, y en el cual no hay una organización política y administrativa centralizada, siendo los tipos de vivienda similares, configurando un tipo de organización familiar homogéneo (Pelissero 1995).

Por ello, no consideramos que esta evidencia sea suficiente, como proponen otros autores, para hablar de grupos de élites en el Tardío, ni de alianzas a un nivel macrorregional (Nielsen 1996) ${ }^{4}$, así como tampoco de una división de la quebrada de Humahuaca en dos entidades diferenciadas, con Tilcara en el sur y Los Amarillos en el norte como cabeceras políticas, cuyo límite sería el Angosto de Perchel. Creemos que estas interpretaciones son producto de la extrapolación de situaciones propias del período postconquista española, reveladas por estudios etnohistóricos (Sánchez y Sica 1991, 1992-1993; Sica y Sánchez 1992) a contextos preincaicos. Las descripciones de los cronistas europeos corresponden a poblaciones que fueron atravesadas por más de 100 años de dominio por parte del aparato político y militar más grande que haya conocido este hemisferio. Pretender que los relatos de los cronistas, creados con información para nada desinteresada que los habitantes originarios de estas tierras les brindaron, dan real cuenta de las estructuras sociales y políticas que existían en la región antes del arribo del Tawantinsuyu, es otorgarles a estos documentos una importancia desmedida y, en alguna medida, pecar de ingenuidad.

A su vez, creemos que muchas de las ideas que se elaboraron sobre el Período de Desarrollos Regionales en Argentina están construidas a partir de evidencia arqueológica recuperada en contextos incaicos y, como mencionamos, en documentos etnohistóricos.

\section{La Huerta en el Tardío, una visión alternativa}

Considerando los puntos previos, creemos que $\mathrm{La}$ Huerta pudo haber sido durante el Período Tardío un sitio de menor tamaño de lo que hasta ahora se pensaba y no una cabecera regional en pugna por el control de la quebrada troncal y sus recursos. La mayor parte de su superficie construida pudo ser producto de un crecimiento ocurrido en gran medida bajo el control incaico de la región, siendo el Imperio el que promovió su gran desarrollo con el cual el sitio alcanzó las dimensiones que hoy podemos observar.

Con el notable crecimiento de La Huerta impulsado por el Tawantinsuyu, y el simultáneo decrecimiento del que fueron objeto grandes conglomerados del Tardío como Los Amarillos, se produjo una relocalización en el espacio del poder político a nivel regional. El poder circulaba ahora, bajo el dominio

4 Debemos destacar que la postura de este autor no es necesariamente la misma en la actualidad (ver Nielsen 2006). 
incaico, no solo por otras manos y en una forma y escala desconocida hasta ese momento, sino por otros lugares, por otros espacios.

Los incas, al llegar a la quebrada de Humahuaca crearon y perpetuaron nuevas jerarquías sociales, promovieron liderazgos de un tipo y tamaño hasta entonces inédito en la región. Grupos de individuos asociados al poder conquistador habrían conformado una élite, configurando una situación sin precedentes. Así, las jerarquías anteriores a la ocupación incaica debieron ser bastante laxas y temporales, poderes no institucionalizados. Estos eran liderazgos que surgían en determinado tipo de situaciones, como por ejemplo, ante la inminencia de un posible conflicto. Los jefes tras la conquista incaica debieron manejar las fuerzas productivas de la población según las disposiciones del nuevo poder y es aquí donde el Imperio revistió a estas personas de una jerarquía institucionalizada que les permitió movilizar a su gente en pos del beneficio incaico.

Las tumbas del Edificio 2, que contienen el más rico ajuar del sitio, podrían estar dando cuenta de esta situación, la cual no remite necesariamente a la existencia de un grupo detentando el poder anteriormente a los incas. Sino que, en este caso, podría tratarse de un curaca local cuyo poder está dado por la posición y la jerarquía que le otorgó el Tawantinsuyu.

Hemos visto cómo la espacialidad y las acciones y relaciones sociales se constituyen en una relación dialéctica, en un tiempo y lugar histórico particular. Y cómo se hace patente la necesidad de incluir el análisis del espacio al abordar problemáticas sociales, como la expansión, dominación y poder del Tawantinsuyu. Ahora se nos hace claro que el Imperio Inca impuso una nueva espacialidad sobre las poblaciones conquistadas, reestructurando y resignificando el paisaje socialmente construido. La imposición de esta espacialidad ideológicamente constituida produce y reproduce las relaciones de dominación y poder promovidas por el Imperio. El Tawantinsuyu introduce en la sociedad local nuevas prácticas, nuevas jerarquías y un nuevo modo de vivir.

\section{REFERENCIAS CITADAS}

ACUTO, F., 1999a. Paisajes cambiantes. La dominación inca en el valle Calchaquí Norte (Argentina). Revista do Museu de Arqueología y Etnología 3: 143-157.

1999b. Paisaje y dominación: La constitución del espacio social en el Imperio Inca. Sed non satiata. Teoría social en la arqueología latinoamericana contemporánea, A Zarankin y F. Acuto (Eds.), pp. 33-76. Ediciones del Tridente, Buenos Aires.

ACUTO, F., C. ARANDA, C. JACOB, L. LUNA y M. SPROVIERI, 2004. El impacto de la colonización inca en la vida social de las comunidades del valle Calchaquí Norte. Revista Andina 39: 179-201.

ALBECK, M. E., 1992. El ambiente como generador de hipótesis sobre dinámica sociocultural prehispánica en la quebrada de Humahuaca. Cuadernos 3: 95-106.

ALTHUSSER, L., 1988. Ideología y aparatos ideológicos del Estado. Freud y Lacan. Nueva Visión, Buenos Aires.

ASHMORE, W. y B. KNAPP, 1999. Archaeological landscapes: Constructed, conceptualized, ideational. Archaeologies of landscape. Contemporary perspectives, W. Ashmore y B. Knapp (Eds.), pp. 1-30. Blackwell Publishers, Oxford.

BAUER, B. y C. STANISH, 2001. Ritual and pilgrimage in the Ancient Andes. The islands of the Sun and the Moon. University of Texas Press, Austin.
CORNEJO, L., 1999. Los incas y la construcción del espacio en Turi. Estudios Atacameños 18: 165-176.

COSGROVE, D., 1984. Social formation and symbolic landscape. Croom Helm, Londres.

DANT, T., 1999. Material culture in the social world. Open University Press, Buckingham.

DEBENEDETTI, S., 1918. La XIV expedición arqueológica de la Facultad de Filosofía y Letras. Nota preliminar sobre los yacimientos de Perchel, Campo Morado y La Huerta. Publicaciones del Museo Etnográfico 17, Facultad de Filosofía y Letras, Universidad de Buenos Aires, Buenos Aires.

DE MARRAIS, E., L. CASTILLO y T. EARLE, 1992. Ideology, materialization and power strategies. Current Anthropology 37: $15-31$.

EECKHOUT, P., 2004. Reyes del sol y señores de la luna. Incas e Ychsmas en Pachacamac. Chungara, Revista de Antropología Chilena 36 (2): 495-503.

FERNANDEZ DO RIO, S., 2001. El diseño arquitectónico de las sociedades prehispánicas de Huacalera, Jujuy. Tesis para optar al Grado de Licenciada en Ciencias Antropológicas, orientación Arqueología. Facultad de Filosofía y Letras, Universidad de Buenos Aires, Buenos Aires.

FOUCAULT, M., 1976. Vigilar y castigar. Siglo XXI, Buenos Aires. 
GALLARDO, F., M. URIBE y P. AYALA, 1995. Arquitectura inca y poder en el Pucara de Turi. Gaceta Arqueológica Andina 24 (VII): 151-172.

GONZALEZ, A. R., 1980. Patrones de asentamiento incaico en una provincia marginal del Imperio. Relaciones de la Sociedad Argentina de Antropología 14: 63-82.

HAYDEN, D., 1997. Urban landscape History: The sense of place and the politics of space. En Understanding ordinary landscapes, P. Groth y T. Bressi (Eds.), pp. 111-133. Yale University Press, New Haven y Londres.

HILLIER, B. y J. HANSON, 1984. The social logic of space. Cambridge University Press, Cambridge.

HYSLOP, J., 1990. Inka settlement planning. University of Texas Press, Austin.

JACOB, C. e I. LEIBOWICZ, 2005 Ms. Recobrando su protagonismo: Conservación de objetos de madera en el sitio La Huerta (provincia de Jujuy). Ponencia presentada en el $1^{\mathrm{er}}$ Congreso Argentino de Arqueometría, Rosario.

LAFON, C. R., 1956. El Horizonte Incaico en Humahuaca. Anales de Arqueología y Etnología XII: 63-74.

LAWRENCE, D. y S. LOW, 1990. The built environment and spatial form. Annual Review of Anthropology 19: 453-505.

LEIBOWICZ, I., 2006 Ms. Construyendo poder en La Huerta de Huacalera. Ponencia presentada en las VII Jornadas de Jóvenes Investigadores en Ciencias Antropológicas del Instituto Nacional de Antropología y Pensamiento Latinoamericano, Buenos Aires.

MEYERS, A. y C. ULBERT, 1997. Inka archaeology in the Eastern Bolivia: Some aspects of the Samaipata Project. Tawantinsuyu: An International Journal of Inka Studies 3: 80-85.

MILLER, D. y C. TILLEY, 1983. Ideology, power and prehistory: An introduction. En Ideology, power and prehistory, D. Miller y C. Tilley (Eds.), pp. 1-15. Cambridge University Press, Cambridge.

MOORE, J., 1996. Architecture and power in the Ancient Andes. Cambridge University Press, Cambridge.

MORRIS, C., 1973. Establecimientos estatales en el Tawantinsuyu: Una estrategia de urbanismo obligado. Revista del Museo Nacional 23: 127-143.

NIELSEN, A., 1988. Un modelo de sistema de asentamiento prehispánico en los valles orientales de Humahuaca, provincia de Jujuy, República Argentina. Comechingonia 6: 127-155.

_ 1989. La ocupación indígena del territorio humahuaca oriental durante los períodos de Desarrollos Regionales e Inca. Tesis Doctoral. Facultad de Filosofía y Humanidades, Universidad Nacional de Córdoba, Córdoba.

1995a. Aportes al estudio de la producción agrícola inca en la quebrada de Humahuaca. Hombre y Desierto 9, vol. 2, pp. 245-256.
- 1995b. Architectural performance and the reproduction of social power. En Expanding archaeology, J. Skibo, W. Walker y A. Nielsen (Eds.), pp. 47-66. University of Utah Press, Salt Lake City.

- 1996. Demografía y cambio social en la quebrada de Humahuaca (Jujuy, Argentina), 700-1535 DC. Relaciones de la Sociedad Argentina de Antropología XXI: 307-354.

2006. Plazas para los antepasados: Descentralización y poder corporativo en las formaciones políticas preincaicas de los Andes circumpuneños. Estudios Atacameños 31: 63-89.

NIELSEN, A. y W. WALKER, 1999. Conquista ritual y dominación política en el Tawantinsuyu: El caso de Los Amarillos (Jujuy, Argentina). En Sed non satiata: Teoría social en la arqueología latinoamericana contemporánea, A. Zarankin y F. Acuto (Eds.), pp. 153-169. Ediciones del Tridente, Buenos Aires.

NIELSEN, A., M. I. HERNANDEZ LLOSAS y C. RIVOLTA, 2004. Nuevas investigaciones arqueológicas en Juella (Jujuy, Argentina). Estudios Sociales del N.O.A. 7: 93-116.

NILES, S., 1992. Inca architecture and sacred landscape. En The Ancient Americas: Art from sacred landscapes, R. Townsend (Ed.), pp. 346-357. The Art Institute of Chicago, Chicago.

OLIVERA, D. y J. PALMA, 1986. Sistemas adaptativos prehispánicos durante los períodos agroalfareros de la quebrada de Humahuaca, Jujuy, República Argentina. Cuadernos del Instituto Nacional de Antropología 11: 75-98.

PALMA, J., 1991. Arquitectura Inca Provincial en Peñas Blancas, quebrada de Humahuaca. Comechingonia 7: 5-13

—1993. Aproximación al estudio de una sociedad compleja: Un análisis orientado en la funebria. Arqueología 3: 41-68.

_-1996. Estructuras de descarte en un poblado prehispánico de la quebrada de Humahuaca. Arqueología 6: 47-67.

1998. Curacas y señores. Instituto Interdisciplinario de Tilcara, Universidad de Buenos Aires, San Salvador de Jujuy.

2000. Urbanismo y complejidad social en la región humahuaca. Estudios Sociales del N.O.A. 3: 1-37.

PELISSERO, N., 1995. El sitio arqueológico de Keta-Kara. Centro Argentino de Etnología Americana (CAEA), Buenos Aires.

RAFFINO, R., 1988. Poblaciones indígenas de Argentina. Urbanismo y proceso social precolombino. Editorial TEA, Buenos Aires.

_ 1993a. Sobre conquistadores y conquistados. En Inka. Arqueología, historia y urbanismo del altiplano andino, $\mathrm{R}$. Raffino (Ed.), pp. 299-318. Corregidor, La Plata.

_Ed.), 1993b. Inka. Arqueología, historia y urbanismo del altiplano andino. Corregidor, La Plata.

-1993c. El dominio inca en el altiplano de Bolivia. En Inka. Arqueología, historia y urbanismo del altiplano andino, $\mathrm{R}$. Raffino (Ed.), pp. 169-212. Corregidor, La Plata. 
RAFFINO, R. y R. ALVIS, 1993. Las ciudades incas en Argentina: Arqueología de La Huerta de Humahuaca. El sistema de poblamiento prehispánico. En Inka. Arqueología, historia y urbanismo del altiplano andino, R. Raffino (Ed.), pp. 37-76. Corregidor, La Plata.

RAFFINO, R. y J. PALMA, 1993. Las ciudades inca en Argentina: Arqueología de La Huerta de Humahuaca. Los artefactos. En Inka. Arqueología, historia y urbanismo del altiplano andino, R. Raffino (Ed.), pp. 93-129. Corregidor, La Plata.

ROSTWOROWSKI, M., 1992. Pachacamac y el Señor de los Milagros. Una trayectoria milenaria. Instituto de Estudios Peruanos, Lima.

SANCHEZ, S. y G. SICA, 1991. Algunas reflexiones acerca de los tilcaras. Avances en Arqueología 1: 81-99.

-1992-1993. Curacazgo y territorios en la quebrada de Humahuaca. El pleito por la sucesión en el curacazgo de Uquía, siglos XVII-XVIII. Avances en Arqueología 2: 36-55.

SHANKS, M., 2000. Culture/archaeology. The dispersion of a discipline and its objects. En Archaeological theory today, I. Hodder (Ed.), pp. 284-305. Polity Press, Cambridge.

SICA, G. y S. SANCHEZ, 1992. Testimonio de una sociedad en transición: El testamento de un curaca. Cuadernos 3: 53-62.

SOJA, E., 1985. The spatiality of social life: Towards a transformative retheorization. En Social relations and spatial structures, D. Gregory y J. Urry (Eds.), pp. 90-127. MacMillan, Londres.

1989. Postmodern geographies. The reassertion of space in critical social theory. Verso, Londres y Nueva York.

THOMAS, J., 1993. The hermeneutics of megalithic space. Interpretative archaelogy, C. Tilley (Ed.), 73-97. Berg Publishers, Oxford.

1996. Time, culture and identity. Routledge, Londres.

2001. Archaeologies of place and landscape. En Archaeological theory today, I. Hodder (Ed.), pp. 165-186. Polity Press, Cambridge.

TILLEY, C., 1994. A phenomenology of landscape: Places, paths and monuments. Berg Publishers, Oxford.

URIBE, M., 2004. El Inka y el poder como problemas de la arqueología del Norte Grande de Chile. Chungara, Revista de Antropología Chilena 36 (2): 313-324.

VAN DE GUTCHE, M., 1999. The inka cognition of landscape: Archaeology, ethnohistory and the aesthetic of alterity. Archaeologies of landscape. Contemporary perspectives, W. Ashmore y B. Knapp (Eds.), pp. 149-168. Blackwell Publishers, Oxford.

ZEVI, B., 1951. Saber ver la arquitectura. Ensayo sobre la interpretación espacial de la arquitectura. Poseidón, Madrid. 
